\title{
Linkage between Obesity and a Marker Near the Tumor Necrosis Factor- $\alpha$ Locus in Pima Indians
}

\author{
R. A. Norman, C. Bogardus, and E. Ravussin \\ Clinical Diabetes and Nutrition Section, National Institute of Diabetes and Digestive and Kidney Diseases, National Institutes of Health, \\ Phoenix, Arizona 85016
}

\begin{abstract}
Because tumor necrosis factor- $\alpha$ (TNF- $\alpha$ ) expression is increased in adipose tissue of both rodent models of obesity and obese humans, it has been considered as a candidate gene for obesity. Pima Indians were scored for genotypes at three polymorphic dinucleotide repeat loci (markers) near the gene TNF- $\alpha$ at 6p21.3. In a sib-pair linkage analysis, percent body fat, as measured by hydrostatic weighing, was linked (304 sib-pairs, $P=0.002$ ) to the marker closest (10 $k b)$ to TNF- $\alpha$. The same marker was associated $(P=0.01)$ by analysis of variance with BMI. To search for possible DNA variants in TNF- $\alpha$ that contribute to obesity, single stranded conformational polymorphism analysis was performed from 20 obese and 20 lean subjects. Primer pairs were designed for the entire TNF- $\alpha$ protein coding region and part of the promoter. Only a single polymorphism located in the promoter region was detected. No association could be demonstrated between alleles at this polymorphism and percent body fat. We conclude that the linkage of TNF$\alpha$ to obesity might be due to a sequence variant undetected in TNF- $\alpha$ or due to a variant in some other closely linked gene (J. Clin. Invest. 1995. 96:158-162.) Key words: sib-pair - body composition - body mass index • insulin resistance • human genetics
\end{abstract}

\section{Introduction}

The cytokine TNF- $\alpha$ acting as a modulator of gene expression in adipocytes, is implicated in the development of insulin resistance and obesity. In rats, administration of TNF- $\alpha$ results in elevated levels of serum triglycerides (1). In murine adipocytes, TNF- $\alpha$ is capable of suppressing the expression of adipocyte specific enzymes such as lipoprotein lipase (2) and the enzymes involved in fatty acid biosynthesis $(3,4)$. TNF- $\alpha$ has also been associated with obesity in single gene models such as diabetes $(d b)$, obese $(o b)$, tubby $(t u b)$ in the mouse or fatty $(f a)$ in the rat $(5,6)$. In strains homozygous for these mutations, the levels of TNF- $\alpha$ RNA are elevated over the levels in strains that are heterozygous or homozygous normal. In the $f a$ rat, in vivo neutralization by a soluble TNF- $\alpha$ receptor results in decreased insulin resistance (6).

Human obesity is a complex, multifactorial phenotype and,

Address correspondence to Dr. R. A. Norman, NIH, 4214 N. 16th Street, Phoenix, AZ 85016-5319. Phone: 602-263-1556; FAX: 602-263-1647; Email: r6n@cu.nih.gov. No reprints available.

Received for publication 2 February 1995 and accepted in revised form 23 March 1995.

The Journal of Clinical Investigation, Inc.

Volume 96, July 1995, 158-162 on the basis of twin studies, is thought to have a strong genetic component (7). Although it is likely that many genes contribute to obesity, one or more genes may have major influence. Complex segregation analyses of two common measures of obesity, body mass index (BMI) ${ }^{1}$ and percent body fat (percent body fat), have suggested that one or more genes contribute substantially to the development of obesity. For example, a recessive allele is proposed to contribute to high BMIs among a group of families residing in Iowa (8). Among French-Canadians, a similar single gene effect was discerned for fat mass and percent body fat (9). Obesity is considerably more prevalent among Pima Indians than among Caucasians (10). In an effort to uncover a putative major gene that contributes to obesity in Pima, we are screening candidate loci for linkage and association with obesity-related phenotypes. In this study, we report linkage of a marker in the TNF- $\alpha$ region to percent body fat but no associated polymorphism.

\section{Methods}

Subjects and phenotypes. Members of the Gila Indian River Community have been invited every other year to participate in a study on the development of non-insulin-dependent diabetes mellitus (NIDDM) and its complications (11). Descriptive information including height and weight are taken. BMI was calculated as weight $/\left(\right.$ height $\left.^{2}\right)\left(\mathrm{kg} / \mathrm{m}^{2}\right)$. In addition, a 75 gram oral glucose tolerance test is performed to evaluate diabetic status. DNA samples have been collected on over 900 individuals informative for NIDDM and obesity. 764 Individuals from 233 different nuclear families with at least two offspring were used for sibpair linkage analysis. The distribution of sibship size was as follows: 106 families with 2 sibs; 50 families with 3 sibs; 28 families with 4 sibs; 24 families with 5 sibs; 13 families with 6 sibs; 6 families with 7 sibs; 4 families with 8 sibs; and 2 families with 9 sibs. DNA typing data was available on both parents in 40 families, and on one parent in 100 families.

A subset of these individuals have been admitted yearly to the ward of the Clinical Diabetes and Nutrition Section of the NIDDK for clinical studies on the pathogenesis of NIDDM and obesity. Data gathered on this subgroup includes body composition determined by hydrostatic weighing $(12,13)$ and resting metabolic rate (RMR) determined by a ventilated hood system (14). In addition, insulin sensitivity was determined by measuring glucose disposal rates during a two-step hyperinsulinemic, euglycemic clamp (15) with insulin infusion rates of 40 and $400 \mathrm{mU} / \mathrm{m}^{2} \cdot \mathrm{min}$ resulting in insulin plasma concentrations of 130 and $2070 \mu \mathrm{U} / \mathrm{ml}$, respectively (16). DNA genotypes in this clinical subgroup were available from 105 nuclear families with at least two offspring. The total number of offspring available for linkage analysis was 403 with the distribution of sibship size as follows: 58 families with 2 sibs; 30 families with 3 sibs; 9 families with 4 sibs; 1 family with 5 sibs; 5 families with 6 sibs; 1 family with 7 sibs; and 1 family with 9

1. Abbreviations used in this paper: BMI, body mass index; NIDDM, non-insulin-dependent diabetes mellitus; RMR, resting metabolic rate; TNF- $\alpha$, tumor necrosis factor alpha; TNFir24, TNF- $\beta$.ir2/TNF- $\beta$.ir4. 
Table I. Characteristics of the Pima Sibs Used in Linkage Analysis of Percentage Body Fat, RMR, Fasting Insulin, and Glucose Disposal

\begin{tabular}{lclcl}
\hline & \multicolumn{2}{c}{ Female } & \multicolumn{2}{c}{ Male } \\
\hline & \multicolumn{3}{c}{$\mathrm{n}=115$} & \multicolumn{2}{c}{$\mathrm{n}=162$} \\
Age $(\mathrm{yr})$ & $28 \pm 6$ & $(18-45)$ & $28 \pm 6$ & $(18-53)$ \\
Weight $(\mathrm{kg})$ & $79.0+19.9$ & $(43-132)$ & $88.6+23.5$ & $(35-179)$ \\
Height $(\mathrm{cm})$ & $159.5+5.0$ & $(146-172)$ & $171.7+5.4$ & $(158-188)$ \\
BMI $\left(\mathrm{kg} / \mathrm{m}^{2}\right)$ & $37.1+9.2$ & $(18.7-69.7)$ & $34.5+9.4$ & $(18.1-62.1)$ \\
Body fat $(\%)$ & $46 \pm 7$ & $(23-59)$ & $33 \pm 8$ & $(11-53)$ \\
Fat mass $(\mathrm{kg})$ & $44.3 \pm 17.9$ & $(12.9-120.9)$ & $36.7 \pm 20.5$ & $(6.2-140.3)$
\end{tabular}

Each data point was the individuals mean value among all visits with nondiabetic status. Values are means $\pm S D$. Ranges are in paratheses.

sibs. DNA genotypic data was available on both parents in 29 families and on one parent in $\mathbf{5 2}$ families. Only data from nondiabetic individuals or before the development of NIDDM were used for the analysis. Relevant characteristics of this group are given in Table $I$.

Genetic markers. A dinucleotide repeat marker, TNFB.IR2/ TNFB.IR4 (abbreviated in this paper as TNFir24), was selected from the Human Genome Database (GDB) based upon its high heterozygosity ( $\mathrm{H}=0.86$ among Asians) and location very near the TNF- $\alpha$ gene, just $5^{\prime}$ to the start site of TNF- $\beta$ and some 10,000 bp from TNF- $\alpha$ (17). Since evidence of linkage to percent body fat was found at this marker (See Results), two additional, polymorphic markers (D6S273 and D6S291) were subsequently scored. These markers are separated by $3 \mathrm{cM}$ and the location of these markers in the vicinity of TNF- $\alpha$ was inferred from the genetic map (18) (GDB Id: G00-138-311).

$25-50 \mathrm{ng}$ of genomic DNA was amplified in a volume of 5-10 $\mu \mathrm{l}$ for 27 cycles in sets of 90 samples each. For thermal cycle amplification of each set, $\sim 4$ pmol of one primer from each pair was radioactively labelled with $\left(\gamma-{ }^{32} \mathrm{P}\right)$ ATP $(222 \mathrm{TBq} / \mathrm{mmol})$ (NEN/Dupont, Wilmington, DE) using T4 polynucleotide kinase (New England Biolabs, Beverly, MA). Components of the amplifications were at standard concentrations (Perkin-Elmer, Norwalk, CT) except the primers which were $1.5 \mu \mathrm{M}$. $1.5 \mu \mathrm{l}$ of each sample was loaded onto $30 \times 40 \mathrm{~cm} 6 \%$ polyacrylamide, $8 \mathrm{M}$ urea gels with pockets formed by 108 tooth combs (Marshfield Machine Corp., Marshfield, WI) cut to fit a $30 \mathrm{~cm}$ width. Fifteen loadings with a 6 channel pipettor (Hamilton) put the 90 samples onto a single gel. Size standard was a M13mp18 T-track sequencing reaction using $\left(\alpha{ }^{35} S\right)$ and sequenase (USB). Gels were dried and exposed to $\mathrm{x}$-ray film (Eastman Kodak Co., Rochester, NY) for 1 to 2 d. Images were scanned and analyzed with a Bioimage Image Analyzer and accompanying Bioimage STRP software (Millipore, Boston, MA). Allele scorings were merged to DNA identification template files corresponding to each PCR set of 90 . Two independent scorings by different persons were performed and scoring disagreements were resolved by retyping, if necessary.

Statistical analyses. Because most of the individuals had sequential visits to the research unit and thus multiple measures of BMI, percent body fat and RMR, single values for each individual were selected or calculated and used in linkage analysis. For BMI, the maximum value was selected from all visits at which the individual was not diabetic. Presumably, the measure at this visit more accurately represents the attainable BMI in the absence of NIDDM. BMI was adjusted for the effects of sex and age by multiple linear regression (SAS, Cary, NC). For percent body fat, the average value over all visits was used to minimize inherent experimental errors and adjusted for sex and age; For similar reasons the RMR was averaged over visits and adjusted for sex, fat-free mass, fat mass and age. Fasting plasma insulin concentrations and glucose disposal rates were calculated as described (15). The phenotypic data were examined for outliers before adjustments or link-
Table II. Allele Frequency Estimates of TNF Region Markers in First-Degree Unrelated Pima Indians

\begin{tabular}{cccc}
\hline Allele number & TNFir24 & D6S273 & D6S291 \\
\hline 1 & 0.199 & 0.406 & 0.010 \\
2 & 0.035 & 0.264 & 0.837 \\
3 & 0.001 & 0.219 & 0.122 \\
4 & 0.636 & 0.090 & 0.024 \\
5 & 0.001 & 0.021 & 0.007 \\
6 & 0.082 & & \\
7 & 0.031 & & \\
8 & 0.015 & & 0.284 \\
$H^{*}$ & 0.546 & 0.709 & \\
\hline
\end{tabular}

* Calculated heterozygosity.

age analyses were perform. Plots of residuals, studentized residuals, and Cook's D statistic (19) were examined in various leverage plots of the data. If points were deemed as resulting from errors of measure, they were excluded before linkage analyses were performed.

Sib-pair linkage analysis was performed using the program package S.A.G.E. (version 2.2 for P.C.) (20).

Single-stranded conformational polymorphism detection. Searching for genetic variants in TNF- $\alpha$ was done by means of single-stranded conformational polymorphism detection on polyacrylamide gels. Primer pairs were selected from available sequence (21) to amplify an approximate 150-bp fragment from contiguous regions of the TNF- $\alpha$ coding region and promoter. The TNF- $\alpha$ locus is composed of four exons and the total peptide coding sequence is 699 bases (17). To maximize our capability to detect base substitutions as mobility shifts, primer pairs were designed to amplify DNA segments in the range of $150-170$ base pairs (22). This strategy resulted in two primer pairs for exon 1, one pair each for exons 2 and 3, 4 pairs for exon 4 and 4 pairs extending into the promoter. All primers were designed to have a similar $T_{m}$ of $55^{\circ} \mathrm{C}$ in PCR buffer. Amplifications were performed as described above for genetic markers except that both forward and reverse primers were radioactively labeled. Fragments were resolved on nondenaturing polyacrylamide gels of 1:50 (bis:monomer). Three conditions of electrophoresis were employed for all primer sets: (a) $5 \%$ gel, $5 \%$ glycerol, room temperature; (b) $5 \%$ gel, no glycerol, $5^{\circ} \mathrm{C}$; and $(c) 5 \%$ gel, no glycerol, room temperature. A fourth condition of $5 \%$ gel, $5 \%$ glycerol, $5^{\circ} \mathrm{C}$ generally gave poor results but was used on primer sets where resolution of DNA fragments was adequate for comparisons. Gels were run at a power of 8 watts for 5 to $6 \mathrm{~h}$.

\section{Results}

Linkage analysis. To permit an estimation of identity by descent (IBD) in families that were not fully informative for marker alleles, marker allele frequencies in the Pima population were estimated in a group of first-degree unrelated Pima (Table II). Results of sib-pair linkage analysis for quantitative traits are given in Table III. In the clinical subgroup, linkage was suggested by the regression $(P=0.002)$ for the sib-pair difference in \% body fat on IBD at TNFir24. A plot of this sib-pair regression is presented in Fig. 1. Evidence for linkage was weaker at markers D6S273 and D6S291. In the larger group, there was no evidence for linkage to obesity as estimated from BMI (number of sib-pairs $=874$, effective $\mathrm{df}=384, P=0.096$ ).

Several measures relevant to insulin resistance were also examined for evidence of linkage including fasting insulin and glucose disposal at both low and high insulin infusions. Linkage 
Table III. Sib-Pair Linkage Analyses Results with TNF- $\alpha$ Linked Markers

\begin{tabular}{|c|c|c|c|c|c|c|c|c|c|c|c|c|}
\hline \multirow[b]{2}{*}{ Phenotype* } & \multicolumn{4}{|c|}{ Tnfir24 } & \multicolumn{4}{|c|}{ D6S273 } & \multicolumn{4}{|c|}{ D6S291 } \\
\hline & Sib-pairs & $\mathrm{Df}^{+}$ & $t$ value & $P$ value & Sib-pairs & $\mathrm{Df}^{\ddagger}$ & $t$ value & $P$ value & Sib-pairs & $\mathrm{Df}^{*}$ & $\mathrm{t}$ value & $P$ value \\
\hline Percent body fat (\%) & 304 & 156 & -3.05 & 0.002 & 255 & 138 & -1.49 & 0.048 & 260 & 141 & -1.83 & 0.018 \\
\hline Resting metabolic rate & & & & & & & & & & & & \\
\hline (kcal/day) & 294 & 153 & 0.48 & 0.675 & 247 & 139 & 0.45 & 0.676 & 252 & 142 & -0.14 & 0.440 \\
\hline Log fasting insulin & 299 & 149 & -0.84 & 0.202 & 254 & 139 & -0.72 & 0.238 & 259 & 141 & 0.46 & 0.676 \\
\hline $\begin{array}{l}\text { Low glucose disposal } \\
\text { (mg/kg EBMS.min) }\end{array}$ & 284 & 140 & -1.50 & 0.068 & 239 & 130 & -0.36 & 0.361 & 244 & 132 & 0.93 & 0.824 \\
\hline $\begin{array}{l}\text { High glucose disposal } \\
\text { (mg/kg EBMS.min) }\end{array}$ & 299 & 149 & -0.38 & 0.352 & 254 & 139 & 0.84 & 0.799 & 259 & 141 & 0.31 & 0.620 \\
\hline
\end{tabular}

* Phenotypic data was adjusted as follows: body fat by sex and age; resting metabolic rate by fat mass, fat-free mass, age and sex; glucose disposal was expressed in $\mathrm{mg} / \mathrm{min} \cdot \mathrm{kg}$ of estimated body metabolic size and adjusted by percentage body fat. Low denotes a mean plasma insulin concentration of $30 \mu \mathrm{U} / \mathrm{mol}$ while high denotes a concentration of $072 \mu \mathrm{U} / \mathrm{ml}$ (see Methods). ${ }^{\ddagger}$ Effective sample size.

was not evident for any of these measures of insulin resistance (Table III). Adjustment of these same measures for percent body fat provided no evidence for linkage (data not shown). Similarity, RMR showed no evidence of linkage.

Analysis of TNF- $\alpha$. To explore for an association between variants of TNF- $\alpha$ and the variability in \% body fat, DNA samples from unrelated individuals were screened for singlestranded conformational polymorphisms; 20 from subjects with the highest percent body fat (10 of each sex) and 20 from subjects with the lowest percent body fat. No variants were detected in any of the four exons. The search was extended into the $5^{\prime}$ flanking region immediately adjacent to Exon 1 and eventually included 390 base pairs of sequence upstream of the transcription start site. A mobility shift variant was detected with one of these "promoter" primer pairs. Presumably, this variant is a previously reported polymorphism (23) although we have not confirmed this through sequencing. Each individual with a measure of percent body fat was then scored for this variant. The frequencies of the two variants comprising this polymorphism were 0.19 and 0.81 among unrelated individuals. Although this polymorphism is not nearly as informative as TNFir24, sib-pair linkage analysis of this promoter site weakly supported linkage to percent body fat (number of sib-pairs $=293$, effective $\mathrm{Df}=148, P=0.017$ ).

Associations. Because of the proximity of TNFir24 to TNF$\alpha$, genetic variation at TNFir24 was examined for evidence of association with obesity by analysis of variance. To approximate a random sampling and to avoid the potential confounding effect

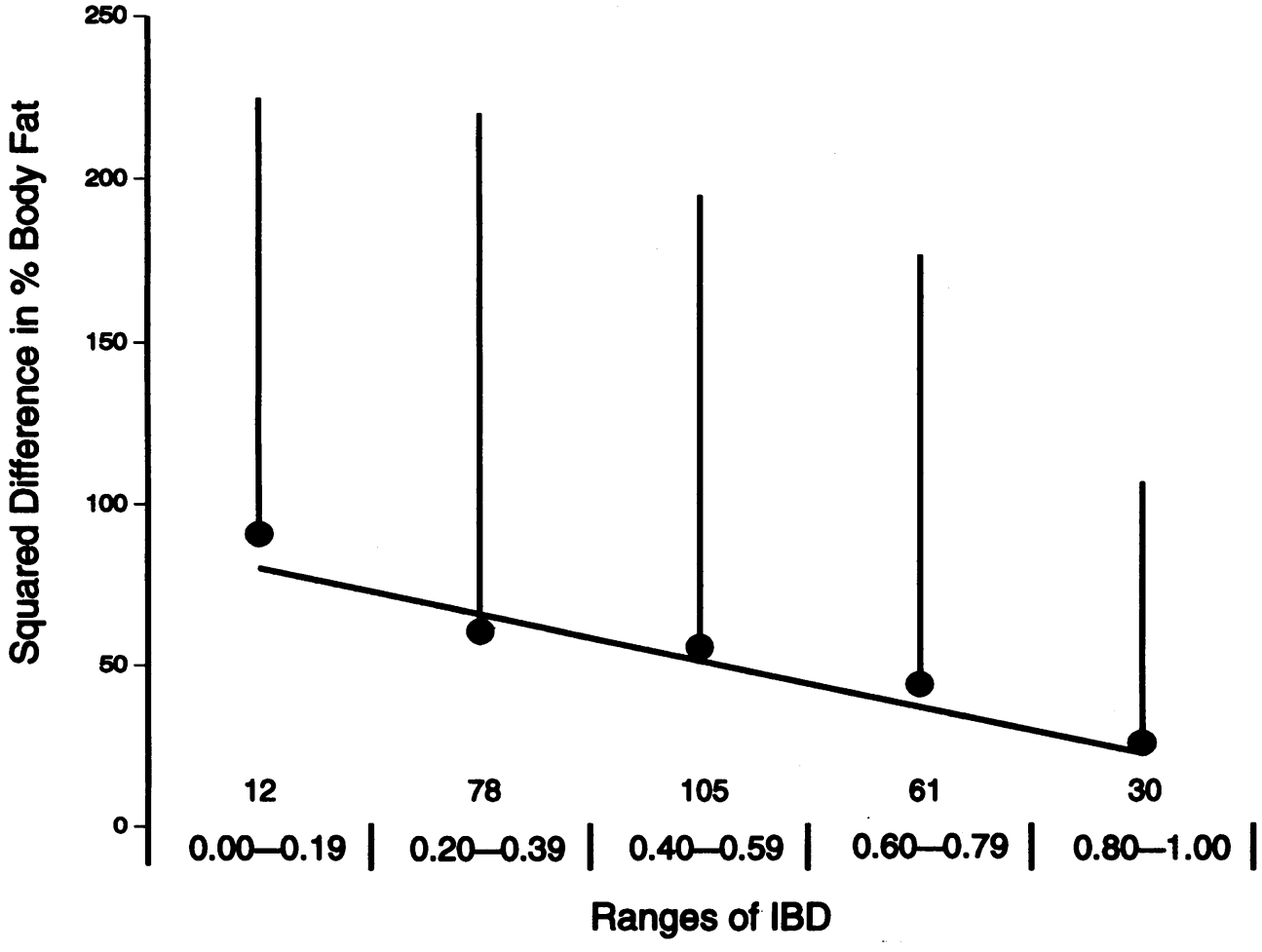

Figure 1. Sib-pair linkage of percent body fat to genetic marker TNFir24. Plot derived by linear regression of the squared sib-pair difference in percent body fat on the genetic identity by descent $(I B D)$ at TNFir24. Filled circles are means for all sib-pairs within the indicated interval for IBD. Vertical lines extend to +2 standard deviations. Plotted regression line is fitted to all individual data points. The number listed just above the IBD interval indicates the number of sib-pairs in the interval. 
Table IV. Differences $(\Delta)$ in Mean BMI and Body Fat Between Genotype 4/4 and the Other Genotypes at TNFir24

\begin{tabular}{lrrrrrrrr}
\hline & \multicolumn{3}{c}{ BMI $\left(\mathrm{kg} / \mathrm{m}^{2}\right)$} & & \multicolumn{3}{c}{ Body Fat (\%) } \\
\cline { 2 - 3 } \cline { 8 - 9 } Genotypes & $n$ & $\Delta$ Mean & s.e. & & $n$ & $\Delta$ Mean & s.e. \\
\hline $4 / 4$ & 143 & $(0.0)$ & 0.67 & & 32 & $(0.0)$ & 2.9 \\
$1 / 1$ & 18 & 4.19 & 3.07 & & 6.1 & 2.8 \\
others/others & 8 & -2.63 & 1.58 & & 3 & -9.1 & 3.7 \\
1/4 & 91 & 1.69 & 0.87 & & 19 & 3.4 & 1.6 \\
4/others & 80 & -1.14 & 0.91 & & 16 & -2.1 & 2.9 \\
1/others & 23 & -2.96 & 1.41 & & 8 & -1.2 & 2.0
\end{tabular}

BMI and body fat were adjusted for the effects of age and sex by linear regression. Associations between BMI and genotypes were assessed by ANOVA; $P=0.01$ for BMI and $P=0.27$ for percentage body fat.

of family, one full-blooded Pima/Papago sibling was selected from each nuclear family. In addition to the subjects from the nuclear families used for linkage analyses, additional unrelated individuals were included in the sample. Because of the numerous rare alleles at the TNFir24 marker, all alleles other than the two most common (alleles 1 and 4 in Table II) were pooled into a single category resulting in a marker of three alleles. The resulting six genotypes were analyzed for association with both BMI $(n=363)$ and percent body fat $(n=84)$. Genotypic differences for BMI and percent body fat are presented in Table IV. BMI was significantly $(P=0.01)$ associated with TNFir24 genotypes. This association remained significant when the rare allele homozygotes $(n=8)$ were removed. Individuals homozygous for the 1 allele had a mean BMI that was higher than individuals homozygous for the 4 allele. Mean percent body fat differences among genotypes tended to be similar to BMI differences (Table IV), but percent body fat had fewer samples and was not significantly $P=0.14$ ) associated with TNFir24.

For the promoter variant, evidence of association with either BMI or percent body fat was not found (data not shown). Because of the near complete association of the 1 allele homozygotes at TNFir24 with the rare allele homozygotes at the promoter variant, percent body fat differences among the promoter site genotypes varied in parallel to those of TNFir24.

\section{Discussion}

In this study on a large number of Pima Indians, a marker (TNFir24) located $10 \mathrm{~kb}$ from TNF- $\alpha$ was linked to percent body fat. The evidence for linkage to body fat was weaker at markers more distant ( $\sim 2$ to $3 \mathrm{cM}$ ) from TNF- $\alpha$, although one marker (D6S291) was not very informative in Pima (heterozygosity 0.28 ) and is expected to have less power to detect linkage. TNFir24 was not linked to BMI even though the number of sib-pairs was nearly three times greater than in the group on which the linkage analysis of percent body fat was done. It is now generally recognized, however, that BMI and percent body fat, although correlated ( $r^{2}=0.64$ in our sample of Pima siblings), cannot be interchanged to estimate obesity since BMI reflects not only fat mass but also lean body mass (9). Both BMI and percent body fat varied among certain TNFir 24 genotypes although the percent body fat variation was not significant. Presumably, TNF- $\alpha$ and TNFir 24 are in linkage disequilibrium and the association of TNFir24 with BMI supports a role for TNF$\alpha$ in obesity.

Despite the linkage to percent body fat, a TNF- $\alpha$ polymorphism associated with body fatness was not found. The lack of polymorphism, however, does not rule out a role for TNF- $\alpha$ in obesity. First, even though optimized, the method of SSCP may not uncover all genetic variants. Second, a variant in the extensive regulatory region flanking TNF- $\alpha$ could alter expression and result in the observed linkage to body fat. $\sim 1,000 \mathrm{bp}$ of 5 ' TNF- $\alpha$ sequence contain regulatory motifs that affect gene transcription (24). Although one "promoter" region variant was detected, most of this 5 ' region was not examined in this study. Third, only the translated region of exon 4 was examined by SSCP and this region represents only about $1 / 3$ of the exon. One report has shown this region to contain endotoxin responsive sequences that affect the production of TNF- $\alpha$ protein at the translational level (25). It is conceivable that a polymorphism in this region may affect the expression of TNF- $\alpha$ and in turn influence body composition.

Additionally, the reported linkage does not indicate that the variant must reside at TNF- $\alpha$. Although linkage disequilibrium of this gene and TNFir24 should increase the power to detect linkage in this region (26), sib-pair linkage does not provide mapping information (27). Linkage may be due to a flanking gene. TNF-beta (28) and the newer lymphotoxin- $\beta$ (29) are located immediately adjacent to TNF- $\alpha$. Presently, it is not clear how these could be considered as candidate genes for obesity. TNF- $\alpha$ is located between the Class III and Class I gene clusters within the major histocompatibility complex $(30,31)$ which cannot be excluded as a cause of the observed linkage. The Class III region is separated from TNF- $\alpha$ by approximately 400 $\mathbf{k b}$ and includes numerous genes, many of which have unknown function (32). Nor can we exclude genes in the HLA region which borders the telomeric side of TNF- $\alpha$ and TNF- $\beta$ by $\sim 250$ bp $(15,28,29)$. New transcripts have recently been uncovered in this region (33), including a large 9.5-kb mRNA that directly flanks the TNF region. It is unclear, at this point, if any genes in this region could be candidates for obesity. There is a reported association of HLA types with BMI among subjects of the Framingham Heart Study (34).

We have selected TNF- $\alpha$, a candidate gene for obesity in Pima, mainly because of the reported overexpression of TNF$\alpha$ mRNA in adipose tissue of rodents that are genetic models for insulin resistance and associated obesity (6). In addition, the levels of TNF- $\alpha$ mRNA and protein in the adipose tissue of obese human subjects were found to be 2.5 times higher than the levels in lean controls and highly correlated with fasting insulin concentration (35).

None of these studies implicate TNF- $\alpha$ as the primary defect. Its elevated expression is one reaction to a cascade of effects brought about by unknown causes. It is conceivable, however, that a genetic variant, as yet undetected, in or near TNF- $\alpha$ could result in modified activity or production at either the protein or message RNA level and, thus, contribute to the prevalence of obesity and insulin resistance among Pima Indians. This view would also include as candidates the two known receptors, TNF R1 and TNF R2 (36), the latter of which is upregulated in response to elevated TNF- $\alpha$ (37).

\section{Acknowledgments}

We thank Dr. Bruce Thompson for review of the manuscript and Dr. Bill Knowler for collection of families. We also thank Warren Apel, 
Robin Olsen, Rachel Janssen, and Vicky Ossowski for assistance in the collection of the data. Some of the data used in preparing this paper were derived from the GDB(TM) Human Genome Data Base accessed at John Hopkins University in Baltimore, MD via Gopher during June, July, and August of 1994.

Some of the results of this paper were obtained by using the program package S.A.G.E., which is supported by a U.S. Public Health Service Resource grant (1 P41 RR03655) from the National Center for Research Resources.

\section{References}

1. Grunfeld, C., and K. R. Feingold. 1991. The metabolic effects of tumor necrosis factor and other cytokines. Biotherapy. 3:143-158.

2. Kawadami, M., P. H. Pekala, M. D. Lane, and A. Cerami. 1982. Lipoprotein lipase suppression in 3t3-11 cells by an endotoxin-induced mediator from exudate cells. Proc. Natl. Acad. Sci. USA. 82:912-916.

3. Pekala, P. H., M. Kawakami, C. W. Angus, M. D. Lane, and A. Cerami. 1983. Selective inhibition of synthesis of enzymes for de novo fatty acid biosynthesis by and endotoxin-induced mediator from exudate cells. Proc. Natl. Acad. Sci. USA. 80:2743-2747.

4. Torti, F. M., B. Deickmann, A. Beutler, A. Cerami, and G. M. Ringold. 1985. A macrophage factor inhibits adipocyte gene expression: an in vitro model of cachexia. Science (Wash. DC). 229:867-869.

5. Hotamisligil, G. S., and B. M. Spiegelman. 1993. Through thick and thin: wasting, obesity, and TNF alpha. Cell. 73:625-627.

6. Hotamisligil G. S., N. S. Shargill, and B. M. Spiegelman. 1993. Adipose expression of Tumor Necrosis factor- $\alpha$ : direct role in obesity-linked insulin resistance. Science (Wash. DC). 259:87-91.

7. Stunkard, A. J., J. R. Harris, N. L. Pedersen, and G. E. McClearn. 1990. The body-mass index of twins who have been reared apart. N. Engl. J. Med. 322:1483-1487.

8. Moll, P. P., T. L. Burns, and R. M. Lauer. 1991. The genetic and environmental sources of body mass index variability: the Muscatine Ponderosity Family Study. Am. J. Hum. Genet. 49:1243-1255.

9. Rice, T., I. B. Borecki, C. Bouchard and D. C. Rao. 1993. Segregation analysis of fat mass and other body composition measures derived from underwater weighing. Am. J. Hum. Genet. 52:967-973.

10. Knowler, W. C., D. J. Pettitt, M. F. Saad, M. A. Charles, R. G. Nelson, B. V. Howard, C. Bogardus, and P. H. Bennett. 1991. Obesity in Pima Indians its magnitude and relationship with diabetes. Am. J. Clin. Nutr. 53:1543s-1551s.

11. Bennett, P. H., T. A. Burch, and M. Miller. 1971. Diabetes mellitus in American (Pima) Indians. Lancet. 2:125-128.

12. Goldman, R. R., and E. R. Buskirk. 1961. Body volume measurement by underwater weighing: description of a method. In Techniques for Measuring Body Composition. J. Brozek and A. Henschel, editors. National Research Council, National Academy of Sciences, Washington, D.C. 78-106.

13. Siri, W. E. 1956. The gross composition of the body. Adv. Biol. Med. Phys. IV. Academic Press, NY. 239-280.

14. Bogardus C., S. Lillioja, E. Ravussin, W. Abbott, J. K. Zawadzki, A Young, W. C. Knowler, R. Jacobowitz, and P. P. Moll. 1986. Familial dependence of the resting metabolic rate. N. Engl. J. Med. 315:96-100.

15. Lillioja S., D. M. Mott, B. V. Howard, P. H. Bennett, H. Yki-Jarvinen, D., Freymond, B. L. Nyomba, F. Zurlo, B. A. Swinburn, and C. Bogardus. 1988. Impaired glucose tolerance as a disorder of insulin action. Longitudinal and crosssectional studies in Pima Indians. N. Engl. J. Med. 318:1217-1225.

16. Lillioja S., D. M. Mott, M. Spraul, R. Ferraro, J. E. Foley, E. Ravussin, W. C. Knowler, P. H. Bennett, and C. Bogardus. 1993. Insulin resistance and insulin secretory dysfunction as precursors of non-insulin-dependent diabetes mellitus. Prospective studies of Pima Indians. N. Engl. J. Med. 329:1988-1992.

17. Nedospasov, S. A., I. A. Udalova, D. V. Kuprash, and R. L. Turetskaya.
1991. DNA sequence polymorphism at the human tumor necrosis factor (TNF) locus. Numerous TNF/lymphotoxin alleles tagged by two closely linked microsatellites in the upstream region of the lymphotoxin (TNF-beta) gene. J. Immunol. 147:1053-1059.

18. Weissenbach, J., G. Gyapay, C. Dib, A. Vignal, J. Morissette, P. Millasseau, G. Vaysseix, and M. Lathrop. 1992. A second-generation linkage map of the human genome. Nature (Lond.). 359:794-801.

19. Cook, R. D. 1979. Influential observations in linear regression. J. Am. Stat. Assoc. 74:169-174.

20. S.A.G.E. 1994. Statistical Analysis for Genetic Epidemiology, Release 2.2. Computer program package available from the Department of Biometry and Genetics, LSU Medical Center, New Orleans LA

21. Pennica, D., G. E. Nedwin, J. S. Hayflick, P. H. Seeburg, R. Derynck, M. A. Palladino, W. J. Kohr, B. B. Aggarwal, and D. V. Goeddel. 1984. Human tumor necrosis factor: precursor structure, expression and homology to lymphotoxin. Nature (Lond.). 312:724-729.

22. Sheffield, V. C., J. S. Beck, A. E. Kwited, D. W. Sandstorm, and E. M. Stone. 1993. The sensitivity of single-stand conformation polymorphism analysis for the detection of single base substitutions. Genomics. 19:325-332.

23. Wilson, A. G., F. S. di Giovine, A. I. Blakemore, and G. W. Duff. 1992. Single base polymorphism in the human tumour necrosis factor alpha (TNF- $\alpha$ ) gene detectable by $\mathrm{NcoI}$ restriction of PCR product. Hum. Mol. Genet. 1:353.

24. Spriggs, D. R., S. Deutsch, and D. W. Kufe. 1992. Genomic structure, induction and production of TNF- $\alpha$. Immunol. Ser. 56:3-34.

25. Han, J., T. Brown, and B. Beutler. 1990. Endotoxin-responsive sequences control cachectin/tumor necrosis factor biosynthesis at the translational level. $J$. Exp. Med. 171:465-475.

26. Cockerham, C. C., and B. S. Weir. 1983. Linkage between a marker locus and a quantitative trait of sibs. Am. J. Hum. Genet. 35:263-273.

27. Hasemann J. K., and R. C. Elston. 1972. The investigation of linkage between a quantitative trait and a marker locus. Behavior Genetics. 2:3-19.

28. Nedospasov S. A., A. N. Shakhov, R. L. Turetskaya, V. A. Mett, M. M Azizov, G. P. Georgiev, V. G. Korobko, V. N. Dobrynin, S. A. Filippov, and N. S. Bystrov. 1986. Tandem arrangement of genes coding for tumor necrosis factor (TNF-alpha) and lymphotoxin (TNF-beta) in the human genome. Cold Spring Harb. Symp. Quant. Biol. 51 Pt 1:611-624.

29. Browning, J. L., A Ngam-ek, P. Lawton, J. DeMarinis, R. Tizard, E. P. Chow, C. Hession, B. O'Brine-Greco, S. F. Foley, and C. F. Ware. 1993. Lymphotoxin beta, a novel member of the TNF family that forms a heteromeric complex with lymphotoxin on the cell surface. Cell. 72(6):847-856.

30. Spies, T., C. C. Morton, S. A. Nedospasov, W. Fiers, D. Poius, and J. L. Strominger. 1986. Genes for the tumor necrosis factors $\alpha$ and $\beta$ are linked to the human major histocompatibility complex. Proc. Natl. Acad. Sci. USA. 83:86998702.

31. Carroll, M. C., P. Katzman, E. M. Alicot, B. H. Koller, D. E. Geraghty, H. T. Orr, J. L. Strominger, and T. Spies. 1987. Linkage map of the human major histocompatibility complex including the tumor necrosiss factor genes. Proc. Natl. Acad. Sci. USA. 84:8535-8539.

32. Dunham, I. C. A Sargent, J. Trowsdale, and R. D. Campbell. 1987. Molecular mapping of the human major histocompatibility complex by pulsedfield gel electrophoresis. Proc. Natl. Acad. Sci. USA. 84:7237-7241.

33. Marshall, B., C. Leelayuwat, L. J. Abraham, M. Pinelli, and R. L. Dawkins. 1994. Large transcripts from a polymorphic $170 \mathrm{~kb}$ MHC region implicated in susceptibility to autoimmune disease. Immunogenetics. 39:15-20.

34. Fabsitz, R. R., J. M. Nam, J. Gart, A. J. Stunkard, R. A. Price, and P. W. Wilson. 1989. HLA association with obesity. Hum. Hered. 39:156-164.

35. Hotamisligil, G. S., P. Arner, J. F. Caro, R. L. Atkinson, and B. M Spiegelman. 1994. Adipose expression of TNF- $\alpha$ in human obesity and insulin resistance. J. Clin. Invest. 95:2409-2415.

36. Tartaglia, L. A., and D. V. Goeddel. 1992. Two TNF receptors. Immunol. Today. 13:151-153.

37. Winzen, R., D. Wallach, O. Kemper, K. Resch, and H. Holtmann. 1993. Selective up-regulation of the $75-\mathrm{kDa}$ tumor necrosis factor (TNF) receptor and its mRNA by TNF and IL-1. J. Immunol. 150:4346-4353. 